\title{
Editorial for Special Issue: "Archaeological Remote Sensing in the 21st Century: (Re)Defining Practice and Theory"
}

\author{
Dave Cowley $^{1}$, Geert Verhoeven ${ }^{2, *} \mathbb{D}$ and Arianna Traviglia ${ }^{3} \mathbb{D}$ \\ 1 Historic Environment Scotland, John Sinclair House, 16 Bernard Terrace, Edinburgh EH8 9NX, UK; \\ dave.cowley@hes.scot \\ 2 Ludwig Boltzmann Institute for Archaeological Prospection and Virtual Archaeology (LBI ArchPro), Ludwig \\ Boltzmann Gesellschaft GmbH, Franz-Klein-Gasse 1, A-1190 Vienna, Austria \\ 3 Centre for Cultural Heritage Technology, Italian Institute of Technology, via della Liberta' 12, 30178 Venice, \\ Italy; arianna.traviglia@iit.it \\ * Correspondence: geert.verhoeven@archpro.lbg.ac.at
}

Citation: Cowley, D.; Verhoeven, G.; Traviglia, A. Editorial for Special Issue: "Archaeological Remote Sensing in the 21st Century: (Re)Defining Practice and Theory". Remote Sens. 2021, 13, 1431 https://doi.org/10.3390/rs13081431

Received: 23 March 2021

Accepted: 31 March 2021

Published: 8 April 2021

Publisher's Note: MDPI stays neutral with regard to jurisdictional claims in published maps and institutional affiliations.

Copyright: (c) 2021 by the authors. Licensee MDPI, Basel, Switzerland. This article is an open access article distributed under the terms and conditions of the Creative Commons Attribution (CC BY) license (https:// creativecommons.org/licenses/by/ $4.0 /$ )
"Beg, borrow and steal": in many ways, this is a strapline for archaeology as a discipline, and perhaps especially so for archaeological remote sensing? The practice of archaeology places it at the intersection of many disciplines, partly in the humanities, partly scientific in orientation, drawing on a range of fields including Earth sciences, philosophy, and computer science, to name just a few. On the one hand, this is an attribute that makes archaeology such an interesting field. However, it can also be observed that archaeological practice has frequently relied on data and tools developed elsewhere, applied without question and with a superficial understanding of underlying principles, and appropriated theory with only shallow appreciation of the intellectual context in which it was developed. Specifically, in archaeological remote sensing, and despite the steady developments in remote sensing technology over the past three decades, the thoughtful integration of data sources and methods into theoretically aware archaeological practice remains relatively underdeveloped. There is a need, therefore, to critically explore developing praxis in 21st century remote sensing archaeology in a context which recognises the need to understand underlying principles, to assess fitness for purpose of approaches, and to develop more mature methodologically and theoretically aware frameworks.

This is the scope for this Special Issue of the journal Remote Sensing-to explore the use of remotely sensed data from either air- or spaceborne platforms for archaeology and cultural heritage in general and contribute to better integrating remotely sensed data in the discipline of archaeology. The nine papers in this SI address a range of technical and theoretical issues within this framework-looking at aspects of products and workflows across a range of data acquisition technologies (airborne laser scanning, airborne hyperspectral imaging, traditional aerial photography, satellite imaging). In this regard, there is a persistent focus on understanding the characteristics of the datasets applied, the workflows implemented, the opportunities offered by innovative applications, and the framing of relevant archaeological questions.

In archaeological remote sensing, the focus of much research and publication work on technical issues and exemplars of methods and data, with less focus on understanding the past, is a notable characteristic of the last decade or more. This is an understandable response to new technology, but the importance of addressing archaeological questions is foregrounded in a study of lithic resource procurement in the Atacama Desert, Northern Chile, by Borie et al. [1]. This paper makes use of Landsat 8 satellite images, moving beyond the discovery and documentation of archaeological features and sites to a massive landscape scale and an understanding of environmental resources-in this case, lithic raw material used by hunter-gatherer groups. The role of focused field studies introduces a multi-scalar perspective to archaeological understanding in a challenging physical setting. 
The way in which archaeological understanding is generated from airborne and spaceborne remote sensing is considered from a very different perspective in a paper by Raczkowski [2], which presents a critical challenge to any view that assimilating such data into archaeological understanding is through the simple expediency of looking, and that in some way, such "looking" is uncomplicated. The common fixation with visualisations of remotely sensed data, such as airborne laser scanning, is discussed with reference to Heidegger's understanding of technology, exploring how such outputs are seen as representations of the "real world" and the extent to which those perceptions are culturally and theoretically dependent. This paper contributes to a largely undeveloped consideration of epistemology in remote sensing archaeology, which can otherwise be dominated by an inherently positivist, and largely uncritical, perspective.

If the paper by Raczkowski introduces the necessity for understanding the "thinking" behind aspects of remote sensing archaeology, the paper by Gallwey et al. [3] illustrates the need to understand the foundational aspects of new approaches. In this study of deep learning for the semi-automated detection of historic mining remains, the limited availability of archaeological training datasets is discussed with reference to the potential implications of pre-training convolutional neural networks on "general purpose" (i.e., ImageNet) imagery. On the basis that relict mining remains are expressed in surface topography, this study uses a transfer learning approach in which the initial training of the neural network uses Lunar topographic data - that is to say, a dataset (even if it is "off this world") that may have more in common with archaeological features than the multi-use imagery routinely used for pre-training.

The need to establish the foundational aspects of remote sensing is also illustrated in a paper by Guyot et al. [4], dealing with the potential for airborne hyperspectral imaging for the mapping of submerged archaeological remains. While applications of hyperspectral data for terrestrial contexts are well established, and airborne laser bathymetry or acoustic soundings are routinely used in submerged contexts, the use of airborne imaging spectroscopy brings new perspectives. By combining noise reduction, the automated detection of features, and characterisation of morphological and spectral attributes of archaeological structures, the basis for the analytical exploration of such environments is significantly broadened.

The potential for applications of tried and tested approaches in new contexts demonstrated by Guyot et al. is also a theme in the paper by Sevara et al. [5], where the focus shifts to fully exploiting the dimensionality of remote sensing data-in this case, the value of radiometric information in airborne laser scanning to provide further insights about archaeological features. This paper describes a desk-based approach to radiometric calibration through the selection of homogenous areas of interest, which allows a raster reflectance map approximating a monochromatic illumination-independent true orthoimage to be generated. Having demonstrated the value of the approach and negating the lack of in-field calibration data for most airborne laser scanning data, a freely available tool to apply this procedure is introduced.

The value of such tools is well known to all users of the Relief Visualisation Toolbox, which provides a set of techniques to visualise raster elevation datasets in an easy-to-use package. In the paper by Kokalj and Somrak [6], the authors discuss what constitutes useful visualisations, and how their characteristics bear on the visibility of archaeological topographic features. The paper also addresses the inherent complexity that multiple visualisations may bring to the interpretative process, proposing an approach that blends different relief visualisation techniques to allow for the simultaneous display of topographic features in a single image. This paper offers an interesting complement to Raczkowski's [2] and provides the "recipes" for their visualisations and a tool for their computation.

The benefits of integrated workflows and the combination of what might otherwise be distinct areas of archaeological practice are illustrated in the paper by Lambers et al. [7] which reports on the articulation of remote sensing, machine learning, and Citizen Science in a Dutch case study. Underlying this approach is a desire to address the paucity of 
labelled archaeological training datasets for machine learning (see also [3]), and the recognition that Citizen Science can help generate and validate detections of hitherto unknown archaeological objects. This paper, too, offers an explicit, well-documented workflow that aims to ensure effective integration and that the character of outputs from the different processes is understood.

Understanding the character of outputs from data collection strategies is a theme common to the last two papers in this Special Issue. By asking the question of what a satellite system designed for archaeological specifications might look like, McGrath et al. [8] discuss the factors that impose inherent limitations on the archaeological applications of existing satellite data. By presenting a high-level mission architecture for a bespoke satellite system designed from an archaeological specification, the paper provides a simulation analysis that foregrounds the archaeological requirements for a satellite constellation design. This provides insights into data characteristics that should be useful to the users of repurposed satellite data and contributes to thinking about how archaeological and heritage management concerns might be incorporated into the future planning of satellite missions. A key point of this paper is that satellite data can be sourced and used without understanding how they were acquired, which may be an inherent limitation on the considered applications.

While the discussion of a satellite for archaeology is innovative, the valuable application of satellite data in archaeology has a long history, with such data from the 1960s and 1970s, for example, providing valuable historical documents of landscapes that may be long gone or dramatically altered. The benefits of a longer-term perspective on aspects of archaeological practice are discussed by Czajlik et al. [9] in this collection's final paper. The value of differential crop development (cropmarks) in the detection of buried archaeology is well-known, but the authors point out that much of the knowledge about how and why such proxies develop is empirical. They identify the significance of the results of a long-term aerial survey-in this case, in Hungary, over more than three decades-to support systematic analysis against factors such as soil properties and weather patterns to better inform future survey strategies. This is important because cropmark prospection needs to be properly targeted, whether that is to define the most cost-effective conditions under which to task a satellite or to put an aircraft in the air.

Returning to the scope of this collection of papers, there is an aspiration to explore (re)defining practice and theory, including critical discussion on the role of remote sensing within archaeological practice, addressing dislocations that may occur with theoretical concerns, and considering the future symbiosis of practice and theory. We note some positive trends, specifically in the better understanding of underlying assumptions, in the explicit definition of workflows, and in the provision of tools and other mechanisms to standardise, and so ensure the replicability, of work. Perhaps less well-developed is the symbiosis of practice and theory in archaeological remote sensing, and this is unsurprising given the weight of interest in the "technical" aspects of the field of study [2].

We hope that the collation of this Special Issue provides the reader with food for thought on these challenges, and so contributes to archaeological remote sensing as a discipline not so much epitomised by "beg, borrow and steal" but rather a mature interdisciplinary field characterised by explicit, thoughtful, and theoretically engaged approaches to understanding the past.

Acknowledgments: We thank our contributors for their papers and for thoughtfully engaging with the scope of this SI, and the editorial team at Remote Sensing, and specifically Joss Chen, for steering us through the process.

Conflicts of Interest: The authors declare no conflict of interest.

\section{References}

1. Borie, C.; Parcero-Oubiña, C.; Kwon, Y.; Salazar, D.; Flores, C.; Olguín, L.; Andrade, P. Beyond Site Detection: The Role of Satellite Remote Sensing in Analysing Archaeological Problems. A Case Study in Lithic Resource Procurement in the Atacama Desert, Northern Chile. Remote Sens. 2019, 11, 869. [CrossRef] 
2. Rączkowski, W. Power and/or Penury of Visualizations: Some Thoughts on Remote Sensing Data and Products in Archaeology. Remote Sens. 2020, 12, 2996. [CrossRef]

3. Gallwey, J.; Eyre, M.; Tonkins, M.; Coggan, J. Bringing Lunar LiDAR Back Down to Earth: Mapping Our Industrial Heritage through Deep Transfer Learning. Remote Sens. 2019, 11, 1994. [CrossRef]

4. Guyot, A.; Lennon, M.; Thomas, N.; Gueguen, S.; Petit, T.; Lorho, T.; Cassen, S.; Hubert-Moy, L. Airborne Hyperspectral Imaging for Submerged Archaeological Mapping in Shallow Water Environments. Remote Sens. 2019, 11, 2237. [CrossRef]

5. Sevara, C.; Wieser, M.; Doneus, M.; Pfeifer, N. Relative Radiometric Calibration of Airborne LiDAR Data for Archaeological Applications. Remote Sens. 2019, 11, 945. [CrossRef]

6. Kokalj, Z.; Somrak, M. Why Not a Single Image? Combining Visualizations to Facilitate Fieldwork and On-Screen Mapping. Remote Sens. 2019, 11, 747. [CrossRef]

7. Lambers, K.; Verschoof-van der Vaart, W.B.; Bourgeois, Q.P.J. Integrating Remote Sensing, Machine Learning, and Citizen Science in Dutch Archaeological Prospection. Remote Sens. 2019, 11, 794. [CrossRef]

8. McGrath, C.N.; Scott, C.; Cowley, D.; Macdonald, M. Towards a Satellite System for Archaeology? Simulation of an Optical Satellite Mission with Ideal Spatial and Temporal Resolution, Illustrated by a Case Study in Scotland. Remote Sens. 2020, 12, 4100. [CrossRef]

9. Czajlik, Z.; Árvai, M.; Mészáros, J.; Nagy, B.; Rupnik, L.; Pásztor, L. Cropmarks in Aerial Archaeology: New Lessons from an Old Story. Remote Sens. 2021, 13, 1126. [CrossRef] 